\title{
Supporting information \\ Tracking SVOCs' transfer from products to indoor air and settled dust with deuterium-labeled \\ substances
}

Vilma Sukiene, ${ }^{1,2}$ Andreas C. Gerecke, ${ }^{2}$ Yu-Mi Park, ${ }^{3}$ Markus Zennegg, ${ }^{2}$ Martine I. Bakker, ${ }^{4}$ Christiaan J. E. Delmaar, ${ }^{4}$ Konrad Hungerbühler ${ }^{1}$, and Natalie von Goetz ${ }^{1}{ }^{1}$

${ }^{1}$ Institute for Chemical and Bioengineering, Swiss Federal Institute of Technology, (ETH Zurich), Vladimir-Prelog-Weg 1, CH-8093 Zurich, Switzerland

${ }^{2}$ Swiss Federal Laboratories for Material Science and Technology (EMPA), Überlandstrasse 129, CH-8600 Dübendorf, Switzerland

${ }^{3}$ National Institute of Environmental Research (NIER), Environmental Research Complex, Hwangyong-ro 42, Seo-gu, Incheon 404-708, Republic of Korea

${ }^{4}$ National Institute for Public Health and the Environment (RIVM), P.O. Box 1, 3720 BA Bilthoven, The Netherlands

* Corresponding author e-mail: natalie.von.goetz@chem.ethz.ch; phone: +41 446320975

Number of pages: 25, Number of tables: 13, Number of figures: 13 


\section{Contents}

1. Product preparation and installation 3

2. Sampling 3

3. Sample preparation $\quad 4$

4. Quantitative analysis $\quad 5$

5. Quality control 6

$\begin{array}{lll}\text { 6. } & \text { Measured concentrations in air } & 7\end{array}$

7. Measured concentrations in floor dust 10

8. Max/min ratios 16

$\begin{array}{ll}\text { 9. Dust organic matter content } & 17\end{array}$

10. Air exchange rates 17

11. Apartment parameters 19

12. Distribution dynamics assessment 19

13. References 24 


\section{Product preparation and installation}

Plastic product preparation. The travel time of the substance into the artificial plastic product can be estimated by simplifying Fick's law to:

$$
t \approx \frac{x^{2}}{2 D}
$$

With a travel time of 3 days and diffusion coefficients for DBP and DOP of $2 \times 10^{-12}$ and $5 \times$ $10^{-13} \mathrm{~cm}^{2} / \mathrm{s}^{1}$, it can be estimated that the substances entered $10-20 \%$ of the material (DBP entered around $10 \mu \mathrm{m}$ from each side, i.e. around $20 \%$ of the $100 \mu \mathrm{m}$ thick material, DOP around $5 \mu \mathrm{m}$, i.e $10 \%$ of the material).

Installation. The carpet was positioned near to the entrance of the room to increase the frequency of contact, thereby enhancing abrasion, but farer away from the outside entrance, to reduce contamination by larger soil particles. The PV and PT products were installed vertically on a wall, with the PT product being heated up for six hours per day to up to $30^{\circ} \mathrm{C}$. For heating, a lamp with a $60 \mathrm{~W}$ non-energy-saving lamp bulb was placed at a distance of $10-15 \mathrm{~cm}$ from the plastic product. The PH product was installed on a horizontal surface (e.g. book shelf). All the products stayed in the same positions for the whole duration of the project. The participants of the study were asked to use the insecticide spray once a week during the first five weeks of the experiment. It was applied for at least five seconds and sprayed from the middle of the room in all directions. Typically, the insecticide spray was used in the morning. Then the room was closed if possible and intentionally only ventilated in the evening. The apartment with mechanical ventilation (apartment 2) was, however, ventilated continuously.

\section{Sampling}

During the experimental study three types of indoor media samples were collected: active and passive air samples and floor dust samples (see Figure S1).

Floor dust. During each visit floor dust samples were collected by vacuuming the total floor area including the experimental carpet and taking the whole paper vacuum cleaner bag (VCB). The participants were provided with the same kind of new vacuum cleaners (AEG AB 3452), which they could use whenever they wanted, however only for cleaning the floor of the 
experimental room. It was not allowed to use the same vacuum cleaner for cleaning the floor in other rooms or any other surfaces (e.g. sofa, book shelves).

Passive air samples. Monthly indoor air samples were collected using passive air samplers containing polyurethane foam (PUF) disks. Such samplers are used to determine total air concentration as they are capable to collect substances present in both gas phase and particle phase. $^{2}$ Before usage, PUF disks (1.3 cm thick, $14 \mathrm{~cm}$ diameter, Tisch Environmental) were precleaned by Soxhlet extraction with $n$-hexane/dichlomethane (v/v 1/1) for $12 \mathrm{~h}$. The samplers were installed in the experimental rooms in locations with relatively well-mixed air at approximately $1 \mathrm{~m}$ height. The flow rate per sampler (needed to convert concentrations in samples (ng/sampler) to concentrations in air $\left(\mathrm{ng} / \mathrm{m}^{3}\right)$ ) was assumed to be $3.5 \mathrm{~m}^{3} / \mathrm{d}$ as suggested by Zhang et al. ${ }^{3}$

Active air samples. Before collecting active air samples the room was well ventilated for 15 minutes. Then the room was kept closed for 2 hours. Air was pulled through a nozzle with a $37 \mathrm{~mm}$ diameter glass fiber filter (Pall Corporation) by a pump (4.5 L/min for $2 \mathrm{~h}$ ). Prior to deployment, filters had been baked out at $500{ }^{\circ} \mathrm{C}$ for $1 \mathrm{~h}$.

Each sample was wrapped in aluminum foil, sealed in plastic bags and stored at $-20{ }^{\circ} \mathrm{C}$ until analysis.

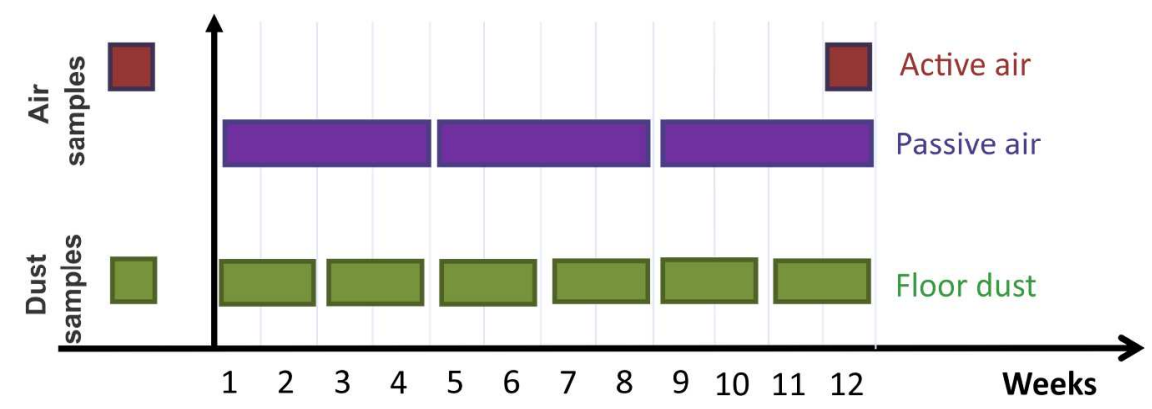

Figure S1. Sampling schedule during the experimental study

\section{Sample preparation}

Prior to analysis, big particles such as feathers or big stones were removed manually from the floor dust samples. Then dust was sieved with a $2 \mathrm{~mm}$ stainless sieve for $20 \mathrm{~min}$ at $100 \mathrm{rpm}$. Dust was kept in the sieve for 10 min for fine particles to settle down. Fraction 1 (F1 > $2 \mathrm{~mm})$ and fraction $2(\mathrm{~F} 2<2 \mathrm{~mm})$ were analyzed separately. 
Dust and air samples were extracted using Soxhlet systems. Samples were placed in individual Soxhlet extractors and extracted for $2 \mathrm{~h}$ by $1 / 1 \mathrm{v} / \mathrm{v}$ hexane/acetone mixture. The volume of the solvent mixture varied between $20-150 \mathrm{ml}$ depending on the size of the sample. $20 \mu 1$ of ${ }^{13} \mathrm{C}_{6}$-labeled di-(2ethylhexyl) adipate $\left({ }^{13} \mathrm{C}_{6}\right.$-DEHA) (concentration of $1 \mathrm{ng} / \mu 1$, Cambridge Isotope Laboratories, Inc.) was spiked to each of the extracts as a recovery standard.

The volume of the extracts was reduced by rotary evaporator to approximately $1 \mathrm{ml}$. Samples were cleaned in florisil columns. The columns were prepared in glass cylinders using glass wool (baked at $400{ }^{\circ} \mathrm{C}, 2 \mathrm{~h}$ ) to close the outlet, adding $1 \mathrm{~g}$ florisil (baked at $400{ }^{\circ} \mathrm{C}$, overnight and deactivated with $3 \% \mathrm{~m} / \mathrm{m}$ pure $\mathrm{H}_{2} \mathrm{O}$ ) and $0.5 \mathrm{~g}$ of $\mathrm{Na}_{2} \mathrm{SO}_{4}$ (baked at $160{ }^{\circ} \mathrm{C}$, overnight) on top.

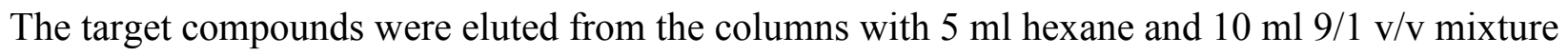
of hexane and acetone. The volume of extracts was reduced to $0.5-1 \mathrm{ml}$ in the rotary evaporator. Finally, a high purity nitrogen stream was used to further reduce the volume of the samples to $100 \mu \mathrm{l}$. For floor dust samples, the solution was concentrated to $1 \mathrm{ml}$ volume. Then, $100 \mu \mathrm{l}$ of the sample was taken and transferred to GC vials for analysis. $10 \mu \mathrm{l}(2.0 \mathrm{ng} / \mu \mathrm{l})$ of ${ }^{13} \mathrm{C}_{4}$-labeled dihexyl phthalate $\left({ }^{13} \mathrm{C}_{4}\right.$-DHP) was added as an internal standard.

\section{Quantitative analysis}

Quantitative sample analysis was performed using the relative response factor method based on the ratio of peak areas of extracted analyte ion and the internal standard. The calibration standards were prepared at $6-9$ levels ranging from $0.05 \mathrm{ng} / \mu \mathrm{l}$ (L1) to $20 \mathrm{ng} / \mu \mathrm{l}$ (L9). Both recovery and internal standards were added to each of the samples.

For samples of different matrices (PUF or dust) separate calibration curves were prepared by spiking standard solutions in the extracts of blank matrix to account for the matrix effect. When the measured concentrations of target substances were higher than the highest calibration level, samples were diluted and re-analyzed within the calibration range. In such cases, recoveries of the samples could not be estimated. For the quantification of diluted samples, a standard calibration curve prepared in pure solvent was used.

Samples were grouped in sets according to their matrix. To account for instabilities of the mass spectrometer a new calibration curve was prepared before analyzing each set of the samples. The 
calibration curve samples were stored at $-20{ }^{\circ} \mathrm{C}$ for approximately one month. Afterwards, the samples were discarded and new calibration curve samples prepared from working solutions.

The calibration curve was obtained by injecting $0.2 \mu 1$ of the prepared standard samples.

Concentrations of target substances in extracts were measured by gas chromatography coupled to mass spectrometry (GC/MS). The analysis was performed in selected ion monitoring (SIM) mode on HP 5973 mass selective detector (Hewlett-Packard). A trifluoropropylmethyl polysiloxane analytical column of $20 \mathrm{~m} \times 0.18 \mathrm{~mm}$ ID (Restek Rtx-200) was used as the stationary phase. Helium was used as carrier gas. Samples were injected at $300{ }^{\circ} \mathrm{C}$ in the pulsed splitless mode. The oven temperature program was started at $60{ }^{\circ} \mathrm{C}$, increased to $120{ }^{\circ} \mathrm{C}$ at $30{ }^{\circ} \mathrm{C} / \mathrm{min}$, then increased to $280{ }^{\circ} \mathrm{C}$ at $10^{\circ} \mathrm{C} / \mathrm{min}$ and held for $1 \mathrm{~min}$. The injector temperature was $300^{\circ} \mathrm{C}$.

In the floor dust samples the signals of the native plasticizers were obstructing the analysis of the target substances. Therefore, to increase MS resolution $(\mathrm{R}=8000)$, the floor dust samples were analyzed with an HRGC Mega 2 series (Fisons Instruments) gas chromatograph coupled to a MAT 95 high resolution mass spectrometer (Thermo Finnigan MAT). The same chromatographic column and temperature program were used. Hydrogen was used as the carrier gas at a pressure of $105 \mathrm{kPa}$.

\section{Quality control}

Quality control measures were conducted to ensure reliability and accuracy of the measurements. Quality control samples included in the study are background, blank and triplicate samples.

Before the study, background dust and active air samples were collected. The background samples were analyzed to verify that the background concentrations of the insecticide tetramethrin, which is used in commercial insecticide production, were below the limits of detection (LODs) $\left(<5.7 \mathrm{ng} / \mathrm{m}^{3}\right.$ air and $<0.24 \mu \mathrm{g} / \mathrm{g}$ dust).

Triplicate samples were analysed to assess the precision of the analytical method. The triplicates were Six passive air samples were divided into quarters. Three quarters of each sample were analyzed separately. Calculated average of relative standard deviations was $20 \%$. Percent differences were typically less than $30 \%$. Only in one sample the relative standard deviations for 
DiBA and DiBP concentrations exceeded 40\%. In two samples, percent differences between the extreme measurements of tetramethrin were $33 \%$ and $43 \%$.

PUF blank samples were used to estimate the contamination of the sampling equipment due to preparation, handling or storage. Concentrations of all the target substances in blank samples were below the detection limits (average of LODs $=0.027 \mathrm{ng} / \mu 1 \mathrm{sample}$ ).

For each analyte, the detection limit was defined as the lowest detected level of the calibration curve of the corresponding matrix. For dust samples, detection limits were calculated as concentrations on a mass-basis and adjusted to each sample depending on its size.

\section{Measured concentrations in air}

In the Table $\mathrm{S} 1$ concentrations in air in $\mathrm{ng} / \mathrm{m}^{3}$ are reported while the following plots represent the concentrations normalized to the initial strength of the source. Non-detected values are replaced by the respective limits of detection.

Table S1. Measured concentrations of target substances in air

\begin{tabular}{|c|c|c|c|c|c|c|c|c|c|c|}
\hline \multirow[b]{2}{*}{ Apartment } & \multirow[b]{2}{*}{ Week } & \multicolumn{9}{|c|}{ Concentration in air, $\mathbf{n g} / \mathrm{m}^{3}$} \\
\hline & & DiBA & DBA & DiBP & DBP & DEHA & DOA & DOP & DEHP & Tetr \\
\hline \multirow{3}{*}{1} & 4 & 1.3 & 2.2 & 2.7 & $<0.069$ & 0.45 & 6.3 & $<0.077^{*}$ & $<0.080$ & 0.74 \\
\hline & 8 & $<0.059$ & 1.5 & 1.2 & $<0.062$ & 0.34 & 1.5 & $<0.069^{*}$ & $<0.072$ & 0.19 \\
\hline & 12 & $<0.054$ & $<0.052$ & 0.45 & $<0.056$ & 0.29 & 1.7 & 0.065 & $<0.065$ & $<0.074^{*}$ \\
\hline \multirow{3}{*}{2} & 4 & 2.4 & 2.9 & 3.6 & $<0.063$ & 0.27 & 0.52 & 0.15 & $<0.073$ & 1.2 \\
\hline & 8 & 0.53 & 1.2 & 1.9 & $<0.058$ & 0.33 & 0.62 & 0.045 & $<0.067$ & 1.4 \\
\hline & 12 & 0.36 & 1.1 & 1.3 & $<0.062$ & 0.48 & 0.20 & $<0.070^{*}$ & 0.55 & $<0.083^{*}$ \\
\hline \multirow{3}{*}{3} & 4 & 6.0 & 10 & 5.7 & $<0.072$ & 0.51 & 0.42 & $<0.080 *$ & $<0.083$ & 12 \\
\hline & 8 & 1.9 & 2.5 & 1.9 & $<0.063$ & 0.62 & 1.2 & $<0.071^{*}$ & $<0.074$ & 3.2 \\
\hline & 12 & 1.2 & 1.7 & 0.80 & 0.32 & 0.54 & 0.34 & $<0.076^{*}$ & 1.5 & 0.083 \\
\hline \multirow{3}{*}{4} & 4 & 5.2 & 9.1 & 4.4 & $<0.15$ & 0.36 & 0.17 & $<0.17$ & $<0.18$ & 12 \\
\hline & 8 & 0.71 & 3.0 & 3.2 & $<0.15$ & 0.40 & 0.15 & $<0.17^{*}$ & $<0.17$ & 3.2 \\
\hline & 12 & 0.49 & 1.2 & 1.8 & $<0.14$ & 0.44 & 0.21 & $<0.16$ & $<0.16$ & 0.35 \\
\hline \multirow{3}{*}{5} & 4 & 4.8 & 8.5 & 3.6 & $<0.072$ & 0.54 & 0.37 & $<0.080^{*}$ & $<0.084$ & 1.7 \\
\hline & 8 & 0.58 & 2.7 & 2.7 & $<0.067$ & 0.63 & 0.36 & 0.065 & $<0.078$ & 1.5 \\
\hline & 12 & $<0.062$ & 0.86 & 1.6 & $<0.064$ & 2.3 & 3.3 & 0.089 & 0.15 & $<0.085^{*}$ \\
\hline
\end{tabular}

* Values that were detected, but could not be quantified 


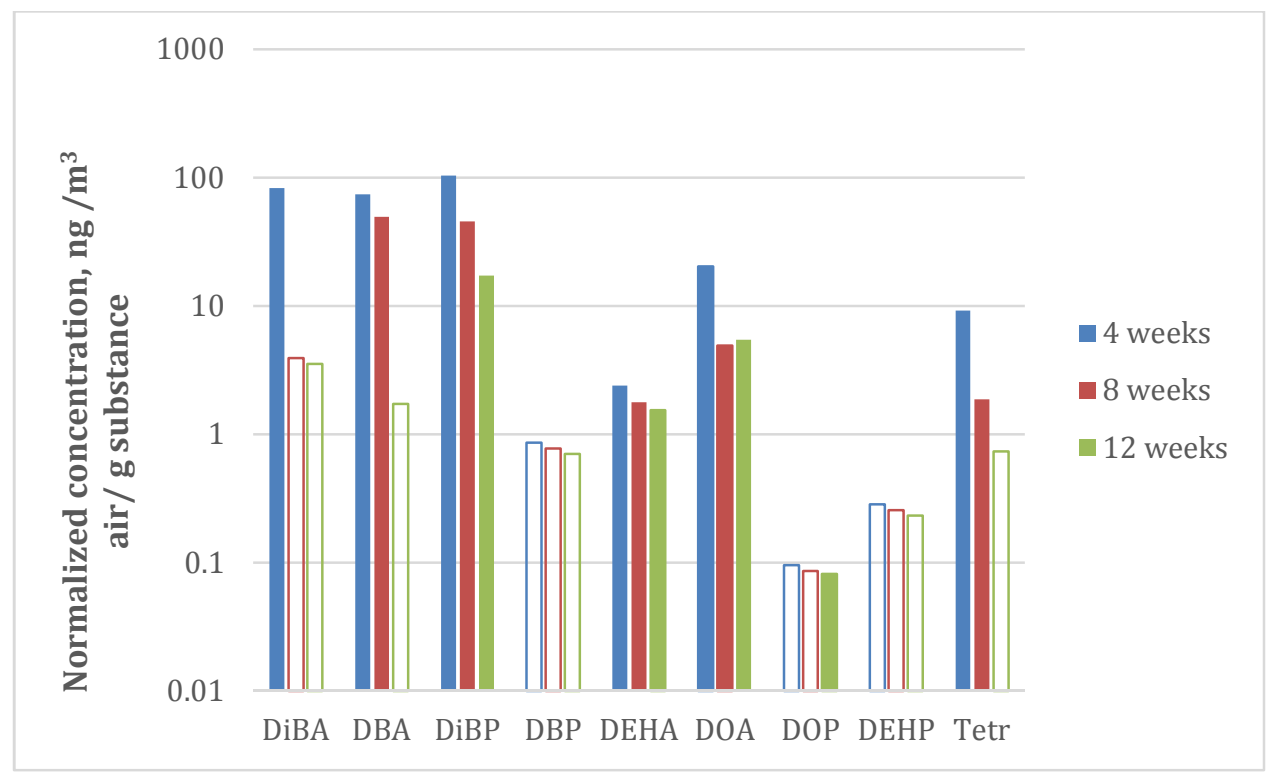

Figure S2. Measured concentrations in apartment 1 air normalized to the initial strength of the sources. Empty bars represent the normalized LODs

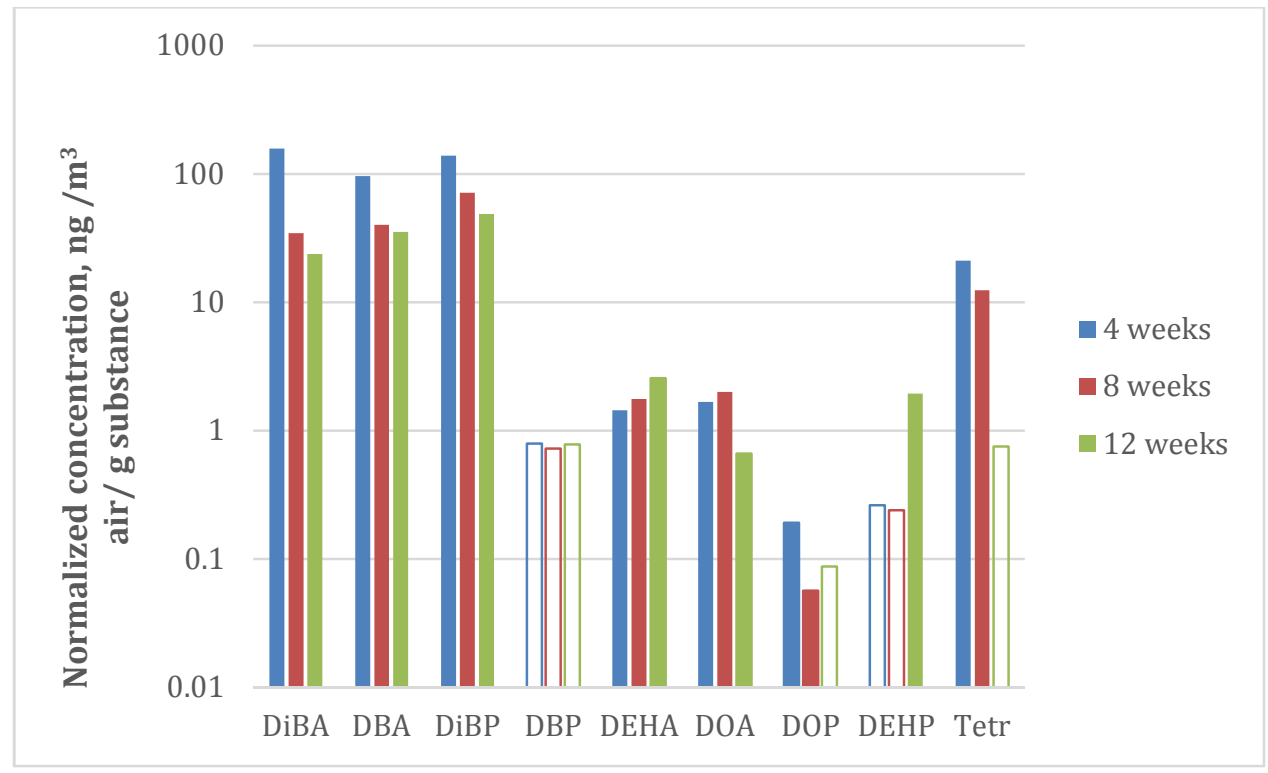

Figure S3. Measured concentrations in apartment 2 air normalized to the initial strength of the sources. Empty bars represent the normalized LODs 


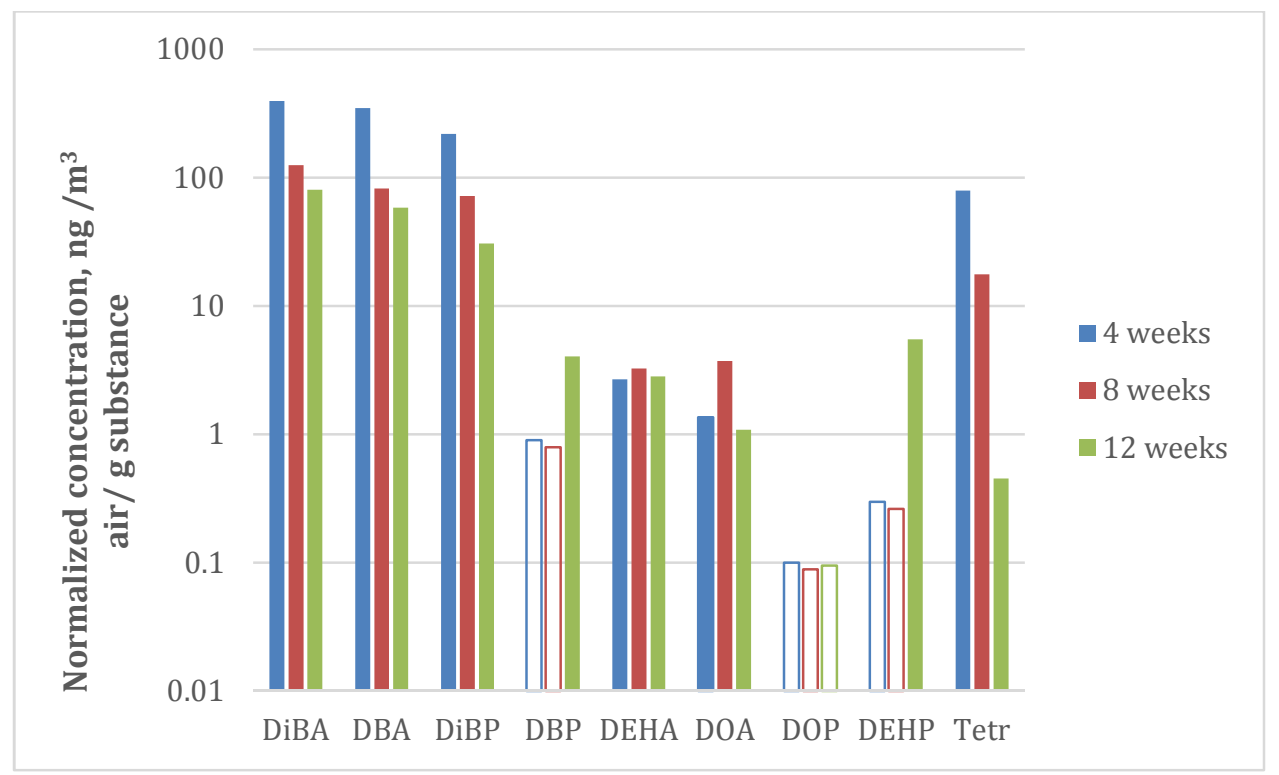

Figure S4. Measured concentrations in apartment 3 air normalized to the initial strength of the sources. Empty bars represent the normalized LODs

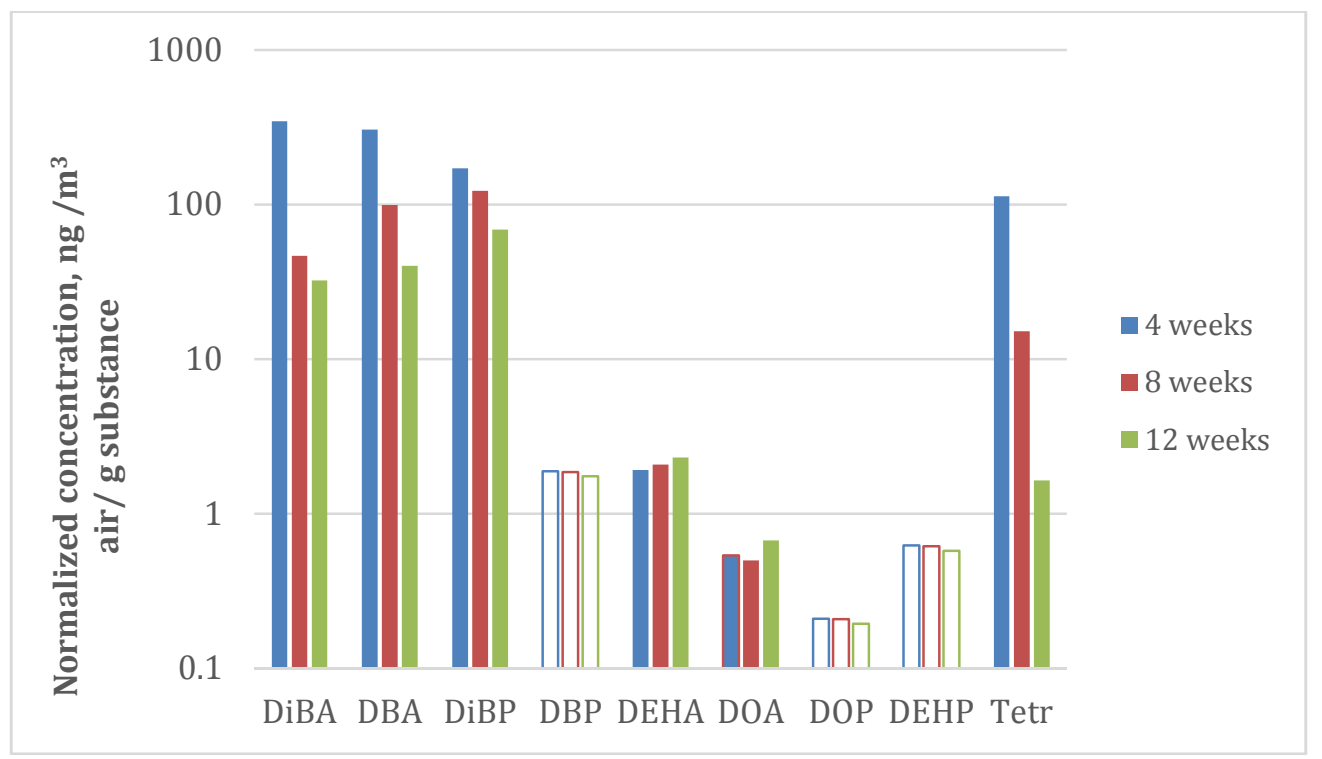

Figure S5. Measured concentrations in apartment 4 air normalized to the initial strength of the sources. Empty bars represent the normalized LODs 


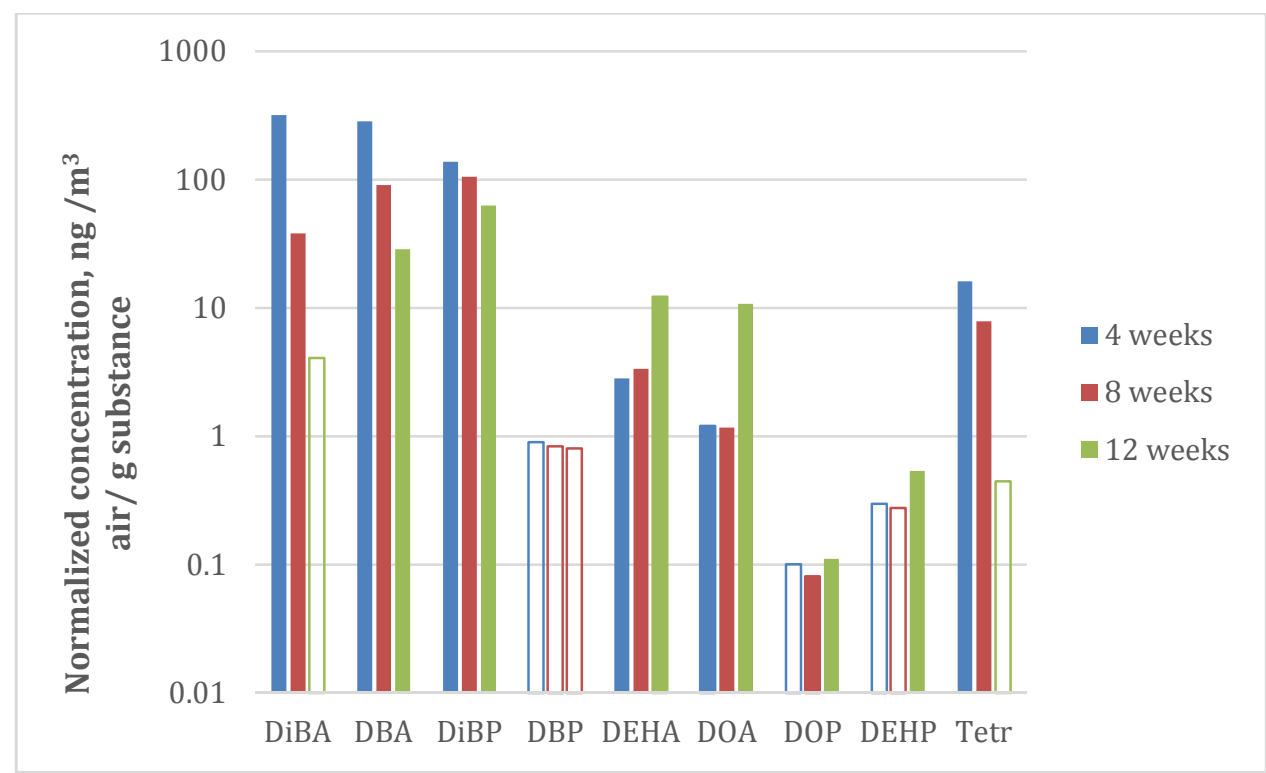

Figure S6. Measured concentrations in apartment 5 air normalized to the initial strength of the sources. Empty bars represent the normalized LODs

\section{Measured concentrations in floor dust}

In the following tables, concentrations in fraction $1(>2 \mathrm{~mm})$ and fraction $2(<2 \mathrm{~mm})$ of the floor dust samples are reported separately. Non-detected values are replaced with corresponding limits of detection calculated on a mass-basis. The following plots show the weighted average concentrations of both floor dust fractions normalized to the initial strength of the source. Empty bars represent the LODs for samples were the substance was not detected in both fractions. 
Table S2. Substance concentrations in apartment 1 floor dust

\begin{tabular}{|c|c|c|c|c|c|c|c|c|c|c|}
\hline & \multirow[b]{2}{*}{ Week } & \multicolumn{9}{|c|}{ Concentration in apartment 1 floor dust $\mu \mathrm{g} / \mathrm{g}$ dust } \\
\hline & & DiBA & DBA & DiBP & DBP & DEHA & DOA & DOP & DEHP & Tetr \\
\hline \multirow{6}{*}{ 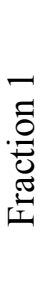 } & 2 & $<0.015$ & 0.036 & 0.69 & 9.6 & 0.077 & $<0.025$ & 240 & 0.17 & 36 \\
\hline & 4 & $<0.013$ & 0.043 & 0.71 & 11 & 0.17 & $<0.022$ & 250 & 0.56 & 50 \\
\hline & 6 & $<0.014$ & $<0.030$ & 0.52 & 9.1 & 0.15 & $<0.024$ & 260 & 0.61 & 81 \\
\hline & 8 & $<0.011$ & $<0.023$ & 0.35 & 9.9 & 0.025 & 1.5 & 230 & 0.77 & 32 \\
\hline & 10 & $<0.010$ & $<0.023$ & 0.26 & 5.3 & $<0.015$ & 0.23 & 130 & 0.17 & 7.5 \\
\hline & 12 & $<0.0078$ & $<0.017$ & 0.20 & 6.8 & 0.37 & 1.3 & 110 & 0.70 & 10 \\
\hline \multirow{6}{*}{ 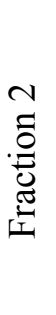 } & 2 & $<0.033$ & 0.061 & 0.84 & 6.3 & 0.053 & $<0.056$ & 130 & 0.13 & 13 \\
\hline & 4 & $<0.031$ & 0.065 & 0.78 & 7.2 & 0.054 & $<0.052$ & 170 & 0.024 & 24 \\
\hline & 6 & $<0.014$ & $<0.029$ & 0.37 & 4.5 & 0.034 & $<0.023$ & 110 & 0.060 & 27 \\
\hline & 8 & $<0.027$ & $<0.059$ & 0.65 & 4.7 & 0.067 & 3.9 & 110 & 0.039 & 12 \\
\hline & 10 & $<0.032$ & $<0.069$ & 0.63 & 3.8 & 0.066 & 0.30 & 82 & $<0.025^{*}$ & 4.2 \\
\hline & 12 & $<0.022$ & $<0.048$ & 0.44 & 3.3 & 0.089 & 0.36 & 78 & 0.065 & 3.3 \\
\hline
\end{tabular}

* Values that were measured but were below LOD - could not be quantified

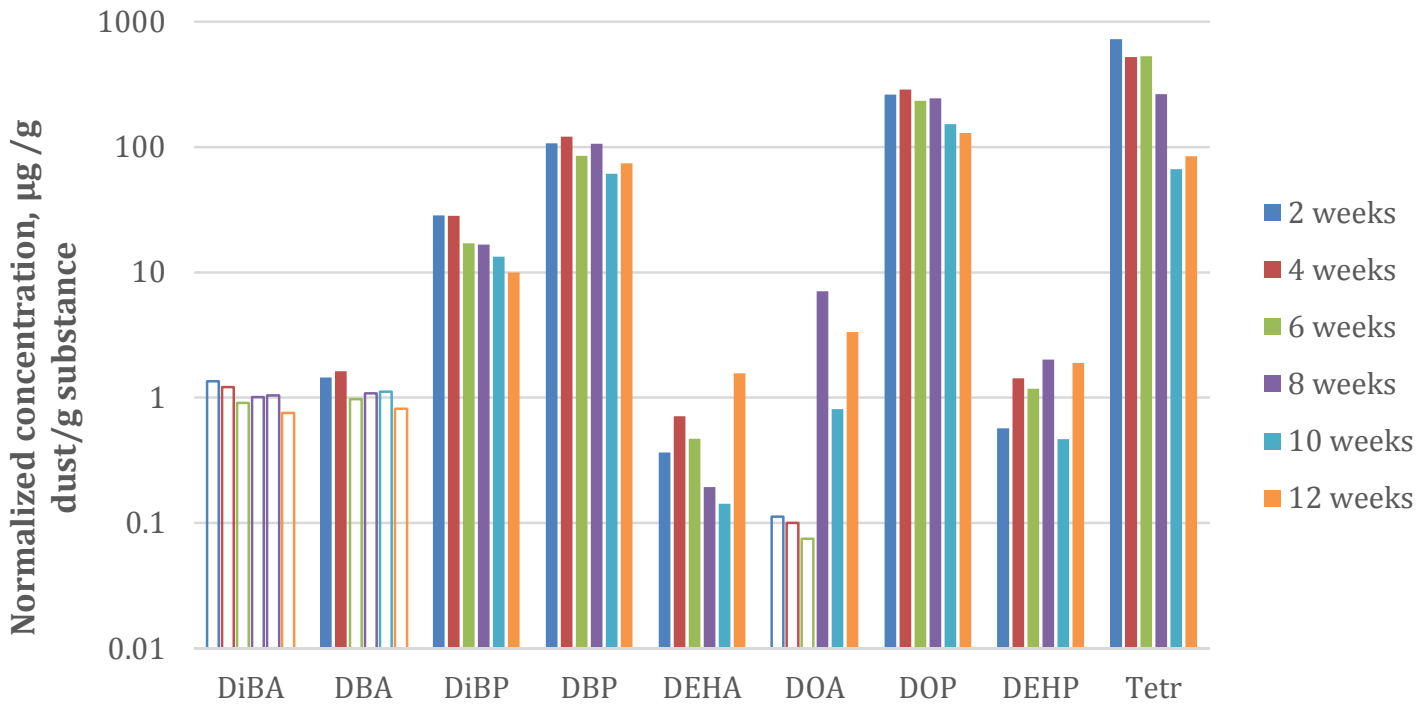

Figure S7. Measured concentrations in apartment 1 floor dust normalized to the initial strength of the sources. Empty bars represent the normalized LODs 
Table S3. Substance concentrations in apartment 2 floor dust

\begin{tabular}{|c|c|c|c|c|c|c|c|c|c|c|}
\hline & \multirow[b]{2}{*}{ Week } & \multicolumn{9}{|c|}{ Concentration in apartment 2 floor dust $\mu \mathrm{g} / \mathrm{g}$ dust } \\
\hline & & DiBA & DBA & DiBP & DBP & DEHA & DOA & DOP & DEHP & Tetr \\
\hline \multirow{6}{*}{ 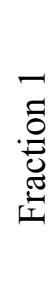 } & 2 & $<0.23 *$ & 0.31 & 1.0 & 1.7 & 0.27 & $<0.26$ & 13 & 0.16 & 66 \\
\hline & 4 & $<0.17^{*}$ & 0.30 & 0.83 & 3.6 & 0.31 & $<0.20$ & 45 & $<0.072 *$ & 15 \\
\hline & 6 & $<0.10^{*}$ & 0.19 & 0.84 & 4.1 & 0.36 & 0.43 & 45 & 0.051 & 87 \\
\hline & 8 & $<0.16$ & 0.22 & 0.95 & 9.1 & 0.47 & $<0.18$ & 120 & 0.087 & 6.7 \\
\hline & 10 & $<0.14$ & 0.20 & 0.78 & 7.6 & 0.60 & 0.26 & 81 & 0.090 & 6.6 \\
\hline & 12 & $<0.12$ & 0.18 & 0.68 & 5.4 & 0.68 & 0.49 & 69 & 0.11 & 14 \\
\hline \multirow{6}{*}{ 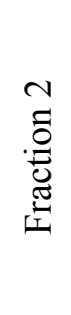 } & 2 & $<0.40^{*}$ & 0.51 & 1.5 & 1.8 & 0.44 & $<0.45$ & 4.9 & 0.24 & 26 \\
\hline & 4 & $<0.37^{*}$ & 0.59 & 1.5 & 3.1 & 0.47 & $<0.42$ & 19 & $<0.16^{*}$ & 9.3 \\
\hline & 6 & 0.16 & 0.24 & 0.80 & 1.9 & 0.25 & 0.62 & 13 & $<0.054^{*}$ & 25 \\
\hline & 8 & $<0.37$ & $<0.46^{*}$ & 13 & 23 & 0.53 & $<0.41$ & 54 & $<0.15^{*}$ & 6.4 \\
\hline & 10 & $<0.31^{*}$ & 0.39 & 12 & 19 & 0.48 & 0.40 & 52 & 0.091 & 7.2 \\
\hline & 12 & $<0.21 *$ & 0.30 & 7.9 & 17 & 0.41 & 0.31 & 67 & $<0.087^{*}$ & 23 \\
\hline
\end{tabular}

* Values that were measured but were below LOD - could not be quantified

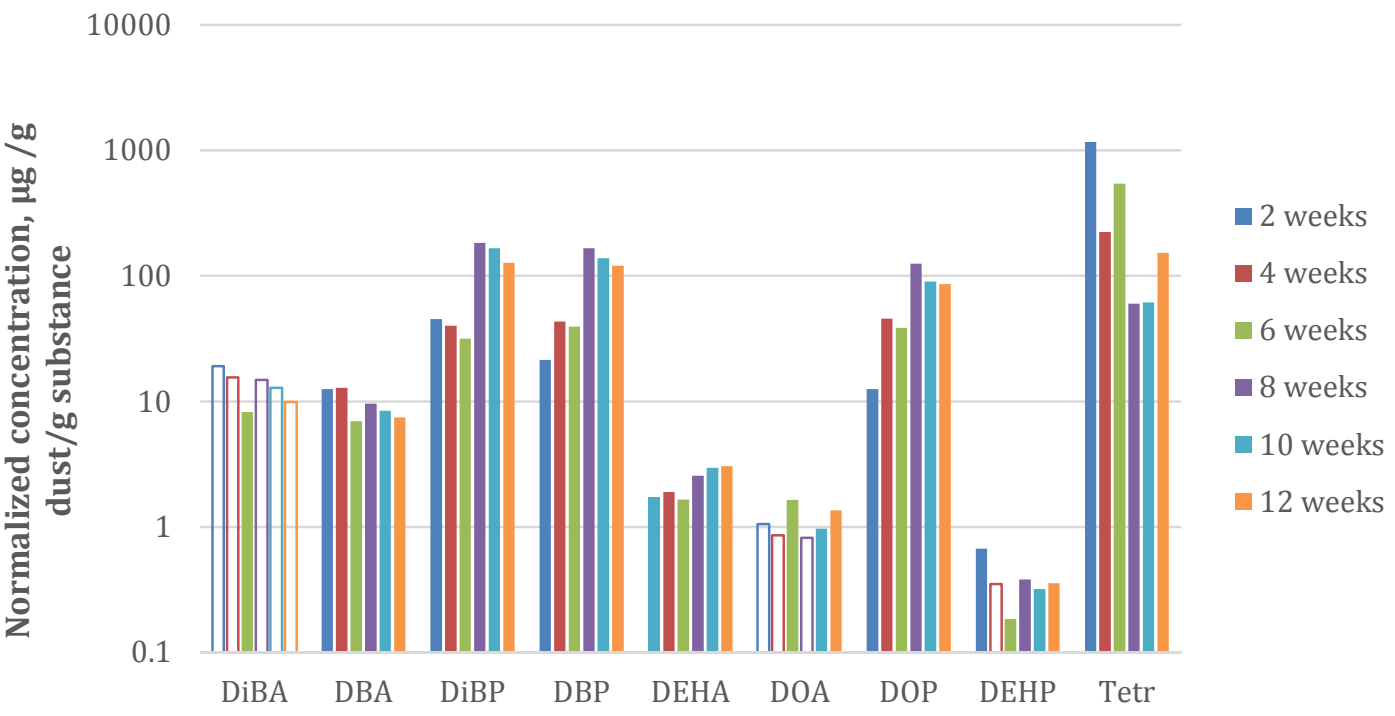

Figure S8. Measured concentrations in apartment 2 floor dust normalized to the initial strength of the sources. Empty bars represent the normalized LODs 
Table S4. Substance concentration in apartment 3 floor dust

\begin{tabular}{|c|c|c|c|c|c|c|c|c|c|c|}
\hline & \multirow[b]{2}{*}{ Week } & \multicolumn{9}{|c|}{ Concentration in apartment 3 floor dust $\mu \mathrm{g} / \mathrm{g}$ dust } \\
\hline & & DiBA & DBA & DiBP & DBP & DEHA & DOA & DOP & DEHP & Tetr \\
\hline \multirow{6}{*}{ 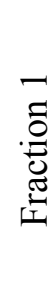 } & 2 & 0.064 & 0.53 & $<0,59^{*}$ & 21 & 0.27 & $<0,34$ & 330 & 0.12 & 58 \\
\hline & 4 & $<0,30$ & 0.034 & $<0,43^{*}$ & 25 & 0.35 & $<0,25$ & 370 & 0.066 & 36 \\
\hline & 6 & $<0,27$ & 0.30 & $<0,39 *$ & 21 & 0.44 & $<0,23$ & 330 & 0.11 & 18 \\
\hline & 8 & $<0,18$ & $<0,19$ & $<0,26^{*}$ & 8.3 & 0.085 & $<0,15$ & 130 & 0.016 & 3.6 \\
\hline & 10 & $<0,28$ & $<0,29$ & $<0,40^{*}$ & 14 & 0.29 & $<0,23$ & 210 & 0.064 & 3.8 \\
\hline & 12 & $<0,29$ & $<0,31$ & $<0,42^{*}$ & 13 & 0.67 & $<0,24$ & 230 & 0.14 & 4.0 \\
\hline \multirow{6}{*}{ 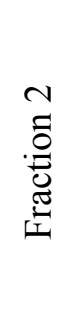 } & 2 & 0.37 & 0.36 & $<0,35^{*}$ & 7.0 & 0.28 & $<0,20$ & 100 & 0.26 & 15 \\
\hline & 4 & $<0,24$ & 0.25 & $<0,35^{*}$ & 6.1 & 0.21 & $<0,20$ & 110 & $<0,14^{*}$ & 12 \\
\hline & 6 & $<0,12$ & $<0,13$ & $<0,18^{*}$ & 5.4 & 0.14 & $<0,10$ & 120 & $<0,072 *$ & 5.9 \\
\hline & 8 & $<2,3$ & $<2,4$ & $<3,3^{*}$ & 82 & 0.73 & $<1,9$ & 1600 & 0.17 & 30 \\
\hline & 10 & $<0,15$ & $<0,16$ & $<0,22 *$ & 2.7 & 0.15 & $<0,12$ & 92 & $<0,088$ & 0.91 \\
\hline & 12 & $<0,20$ & $<0,21$ & $<0,29^{*}$ & 4.5 & 0.26 & $<0,17$ & 62 & $<0,12$ & 1.5 \\
\hline
\end{tabular}

$*$ Values that were measured but were below LOD - could not be quantified

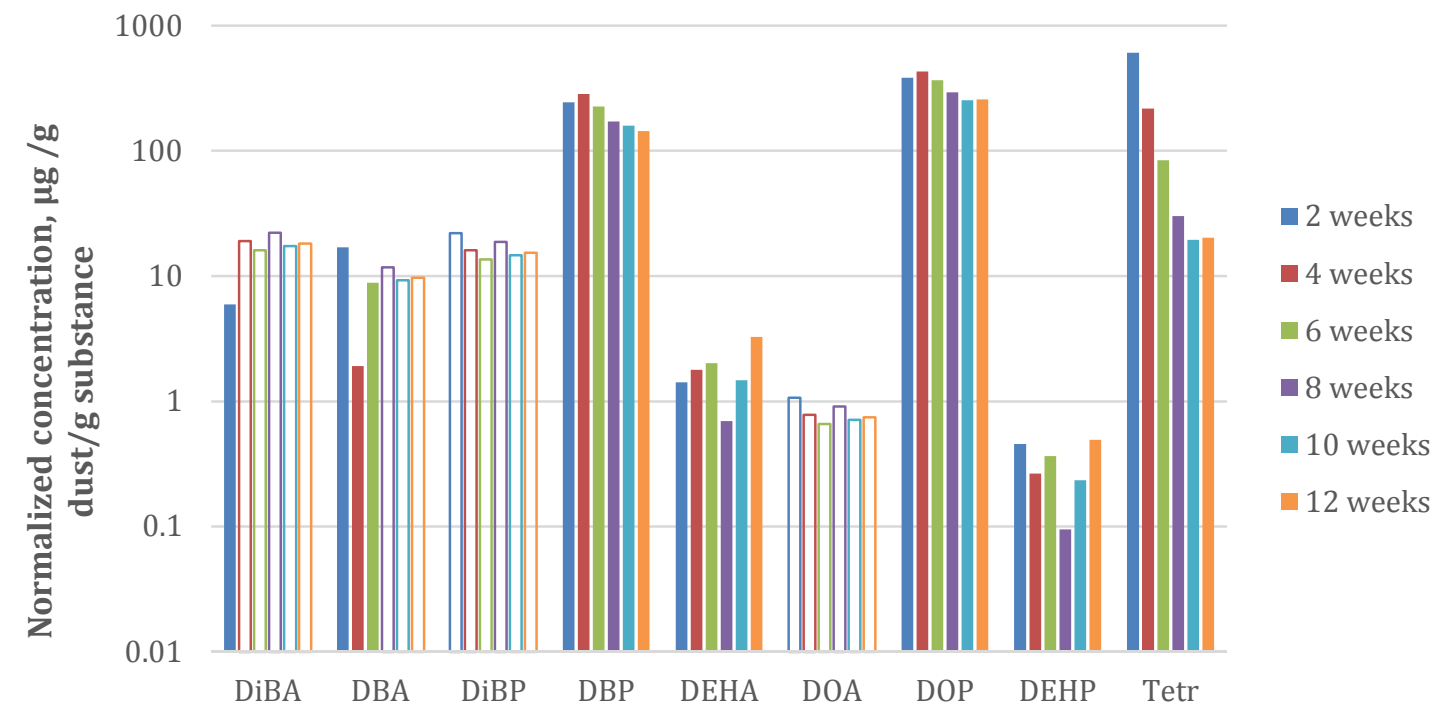

Figure S9. Measured concentrations in apartment 3 floor dust normalized to the initial strength of the sources. Empty bars represent the normalized LODs 
Table S5. Substance concentration in apartment 4 floor dust

\begin{tabular}{|c|c|c|c|c|c|c|c|c|c|c|}
\hline & \multirow[b]{2}{*}{ Week } & \multicolumn{9}{|c|}{ Concentration in apartment 4 floor dust $\mu \mathrm{g} / \mathrm{g}$ dust } \\
\hline & & DiBA & DBA & DiBP & DBP & DEHA & DOA & DOP & DEHP & Tetr \\
\hline \multirow{6}{*}{. } & 2 & 0.15 & 0.23 & 0.69 & 9.2 & 0.20 & $<0.13$ & 130 & 0.13 & 49 \\
\hline & 4 & 0.26 & 0.35 & 1.1 & 12 & 0.34 & $<0.26$ & 180 & 1.7 & 22 \\
\hline & 6 & 0.20 & 0.24 & 0.94 & 12 & 0.30 & $<0.18$ & 200 & 0.21 & 29 \\
\hline & 8 & 0.19 & 0.23 & 0.85 & 13 & 0.29 & $<0.16$ & 220 & 0.37 & 18 \\
\hline & 10 & 0.13 & 0.16 & 0.63 & 13 & 0.22 & $<0.10$ & 230 & 0.72 & 16 \\
\hline & 12 & 0.13 & 0.16 & 0.64 & 15 & 0.23 & $<0.10$ & 250 & 0.10 & 8.1 \\
\hline \multirow{6}{*}{ 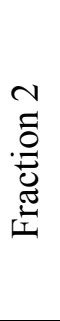 } & 2 & 0.43 & $<0.53^{*}$ & 1.5 & 4.2 & 0.47 & $<0.48$ & 34 & 0.13 & 20 \\
\hline & 4 & $<0.72$ & $<0.90^{*}$ & 2.6 & 5.7 & 0.77 & $<0.81$ & 50 & 0.52 & 14 \\
\hline & 6 & 0.43 & 0.52 & 1.6 & 5.9 & 0.47 & $<0.47$ & 62 & 0.25 & 15 \\
\hline & 8 & 0.45 & 0.56 & 1.6 & 5.9 & 0.48 & $<0.49$ & 76 & 0.29 & 11 \\
\hline & 10 & 0.31 & 0.39 & 1.2 & 5.0 & 0.35 & 0.38 & 67 & 0.40 & 6.4 \\
\hline & 12 & 0.41 & 0.51 & 1.5 & 5.7 & 0.46 & $<0.46$ & 72 & 0.11 & 6.9 \\
\hline
\end{tabular}

* Values that were measured but were below LOD - could not be quantified

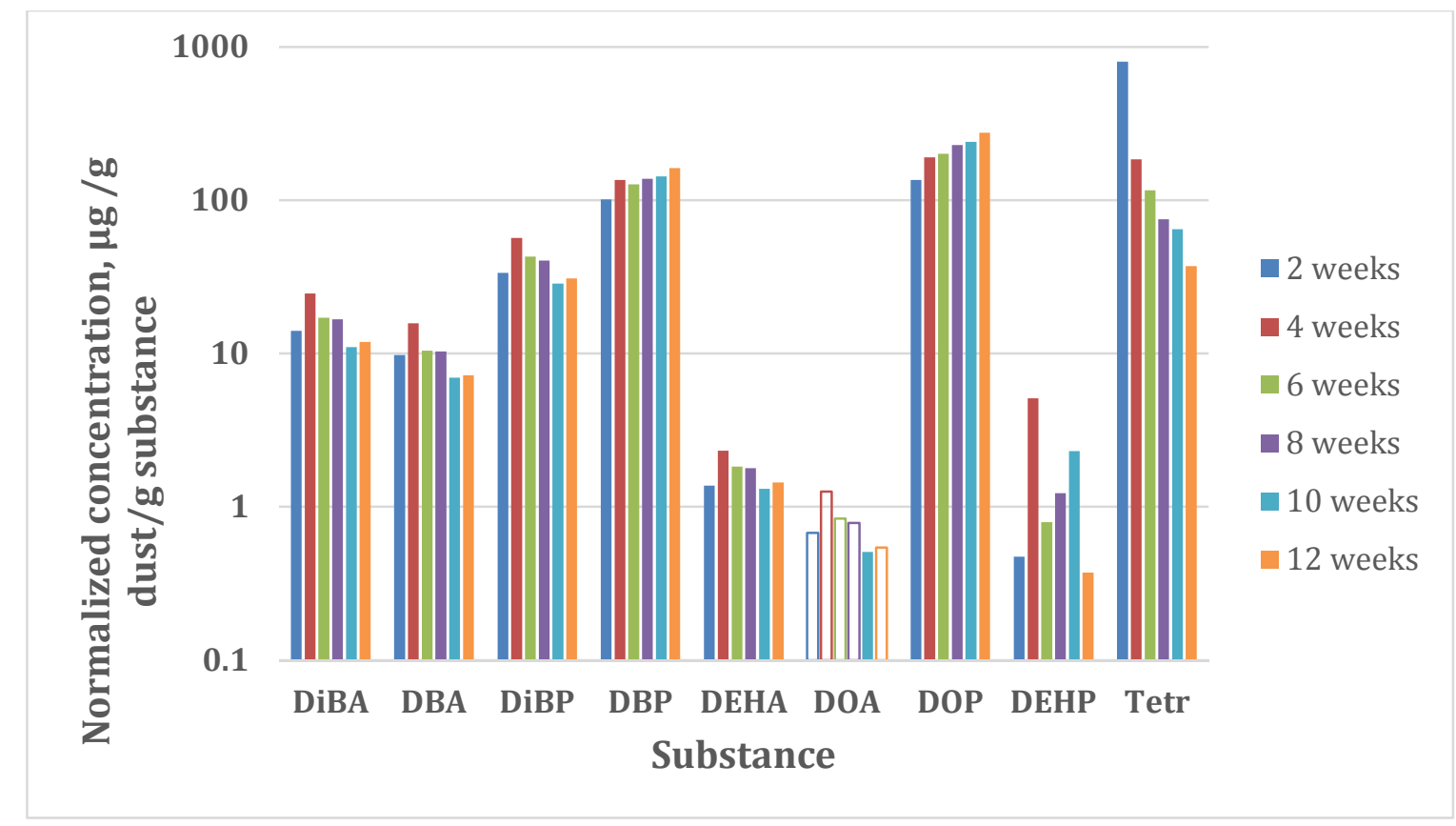

Figure S10. Measured concentrations in apartment 4 floor dust normalized to the initial strength of the sources. Empty bars represent the normalized LODs 
Table S6. Substance concentrations in apartment 5 floor dust

\begin{tabular}{|c|c|c|c|c|c|c|c|c|c|c|}
\hline & \multirow[b]{2}{*}{ Week } & \multicolumn{9}{|c|}{ Concentration in apartment 5 floor dust $\mu \mathrm{g} / \mathrm{g}$ dust } \\
\hline & & DiBA & DBA & DiBP & DBP & DEHA & DOA & DOP & DEHP & Tetr \\
\hline \multirow{6}{*}{ 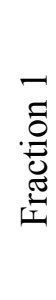 } & 2 & 0.11 & 0.15 & $<0.39 *$ & 3.6 & 0.12 & $<0.11$ & 35 & $<0.040$ & 1.7 \\
\hline & 4 & 0.091 & 0.13 & 0.35 & 4.7 & 0.12 & 0.088 & 63 & $<0.033$ & 4.8 \\
\hline & 6 & 0.10 & 0.15 & 0.45 & 5.6 & 0.17 & 0.20 & 85 & $<0.043$ & 12 \\
\hline & 8 & 0.079 & 0.11 & 0.34 & 4.7 & 0.12 & $<0.082$ & 69 & $<0.030$ & 3.1 \\
\hline & 10 & 0.13 & 0.19 & $<0.56^{*}$ & 4.7 & 0.22 & $<0.15$ & 52 & 0.33 & 2.3 \\
\hline & 12 & 0.13 & 0.16 & $<0.52 *$ & 5.6 & 0.22 & $<0.14^{*}$ & 73 & $<0.053$ & 2.1 \\
\hline \multirow{6}{*}{ 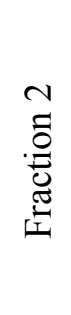 } & 2 & 0.11 & 0.15 & $<0.43^{*}$ & 3.1 & 0.13 & $<0.12$ & 29 & $<0.043$ & 1.8 \\
\hline & 4 & 0.067 & 0.094 & 0.26 & 2.9 & 0.087 & $<0.070$ & 36 & $<0.026$ & 2.7 \\
\hline & 6 & 0.10 & 0.13 & $<0.40^{*}$ & 2.3 & 0.13 & 0.29 & 30 & $<0.041$ & 4.8 \\
\hline & 8 & 0.12 & 0.16 & 0.54 & 3.3 & 0.16 & $<0.14$ & 36 & $<0.051$ & 2.8 \\
\hline & 10 & 0.060 & 0.083 & 0.26 & 2.1 & 0.090 & $<0.069$ & 19 & 0.15 & 1.1 \\
\hline & 12 & 0.14 & 0.18 & $<0.62 *$ & 2.8 & 0.20 & $<0.17^{*}$ & 26 & $<0.063$ & 1.7 \\
\hline
\end{tabular}

$*$ Values that were measured but were below LOD - could not be quantified

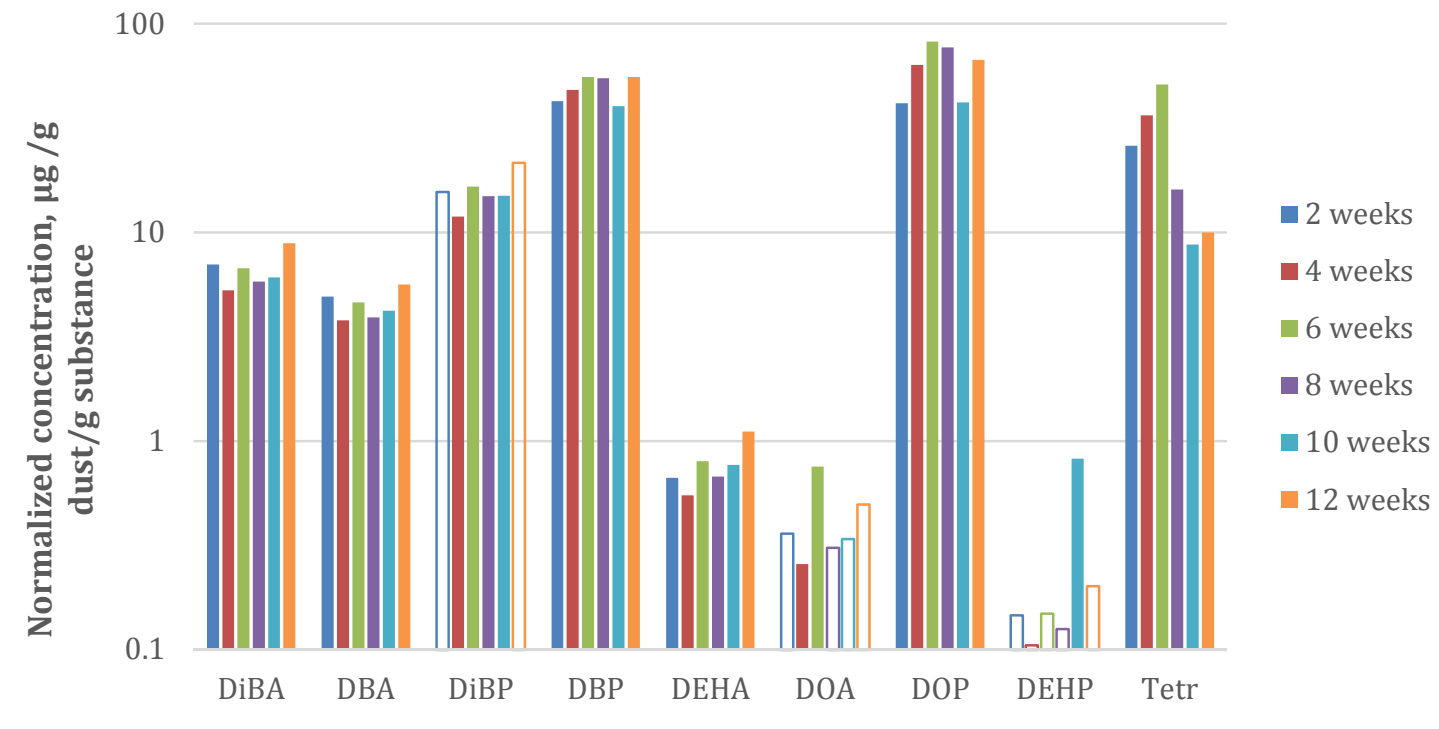

Figure S11. Measured concentrations in apartment 5 floor dust normalized to the initial strength of the sources. Empty bars represent the normalized LODs 


\section{Max/min ratios}

Table S7. Air concentration $\mathrm{max} / \mathrm{min}$ ratio among apartments

\begin{tabular}{|c|c|c|c|c|c|c|c|c|c|}
\hline \multicolumn{10}{|c|}{ Air concentration $\max / \mathrm{min}$ ratio } \\
\hline & DiBA & DBA & DiBP & DBP & DEHA & DOA & DEHP & DOP & Tetr \\
\hline 0 to 4 weeks & 4.8 & 4.7 & 2.1 & 2.4 & 2.0 & 38 & 2.4 & 4.0 & 12 \\
\hline 4 to 8 weeks & 64 & 2.5 & 2.7 & 2.6 & 1.9 & 9.8 & 2.6 & 2.4 & 9.5 \\
\hline 8 to 12 weeks & 45 & 68 & 4.0 & 12 & 7.9 & 16 & 47 & 2.6 & 7.4 \\
\hline Average & 38 & 25 & 2.9 & 5.5 & 3.9 & 21 & 17 & 3.0 & 9.7 \\
\hline Overall average & 14 & & & & & & & & \\
\hline
\end{tabular}

Table S8. Dust concentration max/min ratio between apartments

\begin{tabular}{|c|c|c|c|c|c|c|c|c|c|}
\hline \multicolumn{10}{|c|}{ Dust concentration max/min ratio among apartments } \\
\hline & DiBA & DBA & DiBP & DBP & DEHA & $\mathrm{DOA}$ & DEHP & DOP & Tetr \\
\hline 0 to 2 weeks & 21 & 12 & 5.8 & 11 & 5 & 10 & 30.5 & 9.2 & 45 \\
\hline 2 to 4 weeks & 31 & 7.9 & 7.0 & 6.6 & 4 & 12.5 & 9 & 97.2 & 14 \\
\hline 4 to 6 weeks & 38 & 21 & 6.3 & 5.7 & 4 & 43.8 & 9 & 15.8 & 11 \\
\hline 6 to 8 weeks & 33 & 19 & 20 & 3.1 & 13 & 45.9 & 4 & 32 & 16 \\
\hline 8 to 10 weeks & 21 & 15 & 23 & 3.9 & 26 & 5.7 & 6 & 10 & 7.6 \\
\hline 10 to 12 weeks & 31 & 18 & 16 & 2.9 & 3 & 13.4 & 4 & 18.8 & 15 \\
\hline Average & 29 & 16 & 13 & 5.6 & 9 & 22 & 11 & 30.6 & 18 \\
\hline Overall average & 17 & & & & & & & & \\
\hline
\end{tabular}

Table S9. Air concentration max/min ratio among substances

\begin{tabular}{llllll}
\hline \multicolumn{7}{c}{ Air concentration max/min ratio } \\
& 1 & 2 & 3 & 4 & 5 \\
\hline 0 to 4 weeks & 2200 & 1200 & 7900 & 3300 & 6300 \\
4 to 8 weeks & 1100 & 1300 & 2800 & 1200 & 1300 \\
8 to 12 weeks & 210 & 1100 & 1700 & 710 & 570 \\
Average & 1200 & 1200 & 4100 & 1700 & 2800 \\
\hline Overall average & 2200 & & & \\
\hline
\end{tabular}


Table S10. Dust concentration $\max / \mathrm{min}$ ratio among substances

\begin{tabular}{llllll}
\hline \multicolumn{7}{c}{ Dust concentration max/min ratio } \\
& 1 & 2 & Apartments & \\
\hline 0 to 2 weeks & 13000 & 2200 & 3 & 4 & 5 \\
2 to 4 weeks & 10000 & 1300 & 2000 & 300 & 1200 \\
4 to 6 weeks & 14000 & 3400 & 1100 & 480 & 1100 \\
6 to 8 weeks & 1400 & 620 & 3100 & 580 & 1200 \\
8 to 10 weeks & 1300 & 520 & 1100 & 620 & 250 \\
10 to 12 weeks & 340 & 500 & 690 & 1000 & 660 \\
Average & 6700 & 1500 & 1600 & 890 & 840 \\
\hline Overall average & 2300 & & & \\
\hline
\end{tabular}

\section{Dust organic matter content}

Reported fractions of organic matter of floor dust vary from $20 \%{ }^{4}$ to $33 \%{ }^{5}$ or $43 \%{ }^{6}$ However, none of the experimental rooms in this study had an outside entrance. Therefore it was expected that floor dust collected in these rooms might have a higher organic matter content than the reported values.

The averaged organic matter content of floor dust was determined measuring the organic matter content of both floor dust fractions (F1 $>2 \mathrm{~mm}$ and F2 $<2 \mathrm{~mm}$ ) separately.

Up to one gram of floor dust were placed into the crucibles and heated to $110^{\circ} \mathrm{C}$ for two hours to eliminate water from the samples. Dry samples were stored in the exicator over night to cool down. Room temperature samples were weighted and baked at $400{ }^{\circ} \mathrm{C}$ for 2 hours. The organic matter content was measured gravimetrically at room temperature as the fraction lost during ignition.

The average of measured dust organic matter content was $70 \%$.

\section{Air exchange rates}

The carbon dioxide concentration indoors can be used to assess the air exchange rate (AER) in the apartment: ${ }^{7}$ the carbon dioxide generated by the occupants can be regarded as a tracer gas. ASTM Standard E 741 contains the standard test method for tracer gas dilution over time measurements. ${ }^{8}$ The method is based on the assumption that during the measurement no major 
$\mathrm{CO}_{2}$ sources are present indoors. Then the air exchange rate can be estimated when all the residents leave the building and there are no combustion sources in use. The indoor $\mathrm{CO}_{2}$ concentrations were measured with the electronic data logger OPUS 20, which is a portable realtime sensor with temperature and humidity measurement functions. The instruments were set up between 1 and 2 meters above the floor. Data were collected every 1 min during the whole field study (twelve weeks). The occupancy information of the room was acquired from the self-report daily diary.

Total air exchange rates were calculated from both intentional ventilation through open windows, doors, conditioning systems etc. and unintentional ventilation through cracks in the building envelope. In four apartments the $\mathrm{CO}_{2}$ concentration decay in the unoccupied apartment was used to estimate the unintentional air exchange rate. To assess the total air exchange rate, these data were merged with intentional ventilation rates that were measured while windows were open for time periods specified by the occupants in the time-action dairies. Since the MINERGIE-house (apartment 2) was continuously ventilated, intentional and unintentional ventilation could not be separated.

AER was calculated using Optional Regression Method. Assuming constant air change, AER can be estimated as the slope of the regression line between initial $\left(\mathrm{C}_{0}\right)$ and final $\left(\mathrm{C}_{\mathrm{t}}\right) \mathrm{CO}_{2}$ concentrations:

$\ln \left(C_{t}\right)=-A E R_{t}+\ln \left(C_{0}\right)$

The intentional air exchange rate was estimated as the slope for time periods when $\mathrm{CO}_{2}$ concentrations were decreasing at least for 6 minutes.

To calculate the unintentional ventilation rate of the apartment, time periods were selected during which the apartment was unoccupied. To avoid $\mathrm{CO}_{2}$ concentration fluctuations, the concentration was averaged every $30 \mathrm{~min}$. Then the change of $\mathrm{CO}_{2}$ concentration was calculated only if during the given time period the $\mathrm{CO}_{2}$ concentration was decreasing continuously. In Table S11 the averaged air exchange rates are reported. 
Table S11. Estimated intentional, unintentional and total air exchange rates

\section{Air exchange rate, h-1}

\begin{tabular}{lccc} 
& Unintentional ventilation & Intentional ventilation & Total \\
\hline 1 & 0.02 & 5.96 & 0.49 \\
2 & - & - & $0.10^{*}$ \\
3 & 0.08 & 6.12 & 0.29 \\
4 & 0.03 & 6.08 & 0.11 \\
5 & 0.01 & 5.95 & 0.29 \\
\hline
\end{tabular}

*MINERGIE house, no separation between intentional and unintentional ventilation possible

\section{Apartment parameters}

Table S12. Parameters of the experimental rooms inside the apartments

\begin{tabular}{lccccc}
\hline & \multicolumn{5}{c}{ Apartment } \\
\hline Size, $\mathrm{m}^{2}$ & 1 & 2 & 3 & 4 & 5 \\
Volume, $\mathrm{m}^{3}$ & 36 & 38 & 16 & 14 & 32 \\
Room temperature, ${ }^{\circ} \mathrm{C}$ & 88 & 97 & 39 & 35 & 75 \\
Average temperature, ${ }^{\circ} \mathrm{C}$ & $16.9-24.2$ & $17.6-26.0$ & $20.5-24.7$ & $10.4-27.5$ & $19.1-26.0$ \\
Relative humidity, $\%$ & 21.3 & 22.7 & 22.8 & 19.3 & 21.7 \\
\hline
\end{tabular}

\section{Distribution dynamics assessment}

Weschler and Nazaroff ${ }^{9}$ proposed a simple relationship between the concentrations in the gas phase of ambient air of an apartment $\left(\mathrm{C}_{\text {air }}\right)$ and in the saturated air layer on top of a product $\left(\mathrm{C}_{\text {sat }}\right)$ in the initial phase of the installation of a product.

$\mathrm{C}_{\text {air }}=\frac{\mathrm{A}_{\text {prod }}}{\mathrm{A}_{\text {surf }}} \mathrm{C}_{\text {sat }}$ 
$A_{\text {prod }}$ and $A_{\text {surf }}$ are the surface areas of the emitting product and the total sink surfaces, respectively. Under the assumption that the product concentration $\left(\mathrm{C}_{\text {prod }}\right)$ can be approximated by concentration in octanol $\left(\mathrm{C}_{\mathrm{o}}\right),{ }^{10} \mathrm{C}_{\mathrm{sat}}$ can be substituted by:

$\mathrm{C}_{\mathrm{sat}}=\frac{\mathrm{C}_{\text {prod }}}{\mathrm{K}_{\mathrm{oa}}}$

Where $\mathrm{K}_{\mathrm{oa}}$ is the octanol-air partition coefficient.

Combining (3) and (4) yields:

$\frac{C_{\text {air }}}{C_{\text {prod }}}=\frac{A_{\text {prod }}}{A_{\text {surf }}} \cdot \frac{1}{K_{\text {oa }}}$

or

$\log \frac{C_{\text {air }}}{C_{\text {prod }}}=\log \frac{A_{\text {prod }}}{A_{\text {surf }}}-\log K_{\text {oa }}$

Thus, if the ratio between product and sink surface is constant, a negative linear correlation between the logarithm of the concentration ratio and $\log \mathrm{K}_{\mathrm{oa}}$ is expected.

The gas phase concentrations $\left(\mathrm{C}_{\text {air }}\right)$ were calculated from the total air concentrations $\left(\mathrm{C}_{\text {tot }}\right)$ measured using the approach suggested by Weschler and Nazaroff: ${ }^{4,11}$

$\mathrm{C}_{\text {air }}=\frac{\mathrm{C}_{\text {tot }}}{1+\frac{\mathrm{TSP}}{\rho_{\text {part }}} \times \mathrm{f}_{\text {om_part }} \times \mathrm{K}_{\text {oa }}}$

where TSP is the total suspended particles assumed to be $2 \times 10^{-5} \mathrm{~g} / \mathrm{m}^{3,}, \rho_{\text {part }}$ is the density of airborne particles assumed to be $1 \times 10^{6} \mathrm{~g} / \mathrm{m}^{3},{ }^{9,12} \mathrm{f}_{\text {om_part }}$ is the fraction of organic matter associated with airborne particles assumed to be 0.4 (unitless). ${ }^{9,13}$

Weschler and Nazaroff ${ }^{9}$ proposed an assumption that the affinity of SVOCs for organic matter sorbed to dust or other surfaces is the same as for octanol. Thus, the equilibrium partitioning constant between air and dust $\mathrm{K}_{\text {dust-air }}$ can be estimated on the basis of $\mathrm{K}_{\mathrm{oa}}$ and the organic matter content of dust $\mathrm{f}_{\mathrm{OM} \text {,dust }}$ according to: 
$\mathrm{K}_{\mathrm{oa}}=\frac{C_{\mathrm{o}}}{\mathrm{C}_{\mathrm{air}}} \approx \frac{\mathrm{C}_{\mathrm{OM}, \mathrm{dust}}}{\mathrm{C}_{\mathrm{air}}} \approx \frac{\mathrm{C}_{\mathrm{dust}}}{\mathrm{f}_{\mathrm{OM}, \mathrm{dust}} \cdot \mathrm{C}_{\mathrm{air}}}=\frac{\mathrm{K}_{\mathrm{dust} \text {-air }}}{\mathrm{f}_{\mathrm{OM}, \mathrm{dust}}}$

$\underline{\mathrm{C}_{\text {air }}} \underline{\mathrm{C}}$ product $\underline{\text { ratio }}$

DEHP and DBP were not detected in the air of any apartment during the first time period. Due to the small number of measurements, it is impossible to apply any probabilistic methods to estimate the values for the non-detects. Therefore, we report the ratios estimated substituting non-detects by half of their detection limits. We have considered uncertainties caused by the substitution by calculating lower and upper bounds. The concentration ratio calculated by substituting non-detects with their LOD values (upper bound) are reported in Figure S12. The calculation of the ratio in the log scale is impossible when substituting non-detects with zero, however, any values lower than half of LODs would result in lower ratio values that would even increase the negative correlation. Thus, the negative correlation remains is independent of the substitution of non-detects.

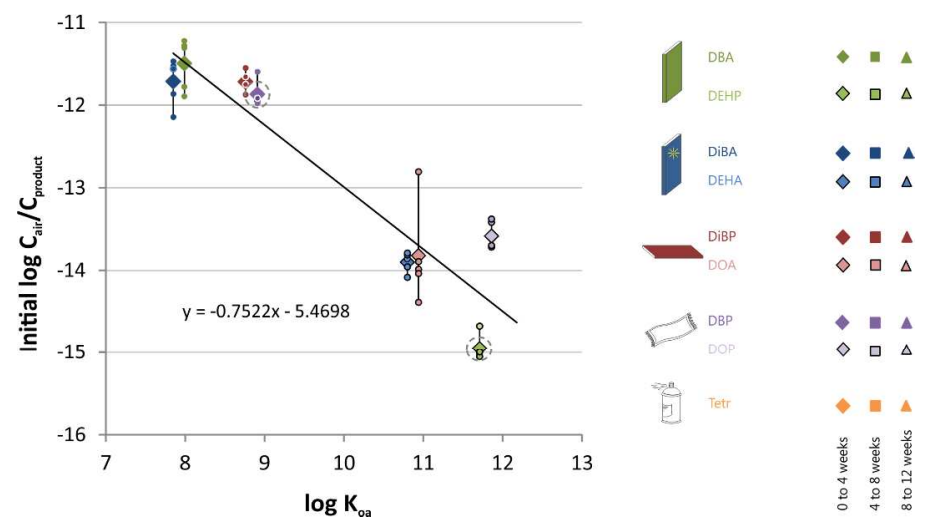

Figure S12. Correlation between $\mathrm{C}_{\mathrm{air}} / \mathrm{C}_{\text {product }}$ and $\log \mathrm{K}_{\mathrm{oa}}$ for the initial phase. The error bars represent the variability of concentration ratios in single apartments. 


\section{Influence of the $\mathrm{K}_{\mathrm{oa}}$ values to the concentration ratio}

To investigate how the selection of $\mathrm{K}_{\mathrm{oa}}$ values would influence the consistency of the experimental results and models, the substance concentration ratios were also calculated using default $\log \mathrm{K}_{\mathrm{oa}}$ values proposed in EpiSuite Version 4 (see Table S13). However, default $\log \mathrm{K}_{\mathrm{oa}}$ values are not consistent in the way they are estimated. These values are calculated from octanolwater partitioning coefficients $\left(\mathrm{K}_{\mathrm{ow}}\right)$ and Henry's constants, some of which are measured experimentally, others are estimated.

Table S13. Default $\log \mathrm{K}_{\mathrm{oa}}$ values proposed in EpiSuite Version 4

\begin{tabular}{llllllllll}
\hline \multicolumn{7}{c}{ Substance } & Reference \\
\hline DiBA & DBA & DiBP & DBP & DEHA & DOA & DEHP & DOP & Tetra & \\
7.9 & 8.0 & 8.8 & 8.9 & 10.8 & 10.9 & 11.7 & 11.9 & 12.2 & EpiSuite* \\
7.9 & 8.0 & 8.4 & 8.6 & 12.9 & 13.0 & 12.6 & 12.1 & 8.9 & Default of EpiSuite \\
\hline
\end{tabular}

*used in this study; calculated from the estimated octanol-water partition coefficients and Henry's constants estimated with bond method

The results obtained using the default $\log \mathrm{K}_{\mathrm{oa}}$ values, however, are very similar to the ones obtained with our selected $\log \mathrm{K}_{\mathrm{oa}}$ values (see Figure 2). Negative correlation between substances $\log \mathrm{C}_{\text {air }} / \mathrm{C}_{\text {product }}$ remain (see Figure S13a). Also substances still can be divided into three groups based on their $\mathrm{C}_{\text {dust }} / \mathrm{C}_{\text {product }}$ concentration ratios (see Figure $\mathrm{S} 13 \mathrm{c}$ ). A significant difference is, however, observed for the tetramethrin $\mathrm{C}_{\text {dust }} / \mathrm{C}_{\text {air }}$ concentration ratio (see Figure $\mathrm{S} 13 \mathrm{~b})$ that is above the equilibrium line. However, the mismatch of the theory and the measurement results might be caused by the underestimation of the default $\mathrm{K}_{\mathrm{oa}}$ value proposed in EpiSuite. 

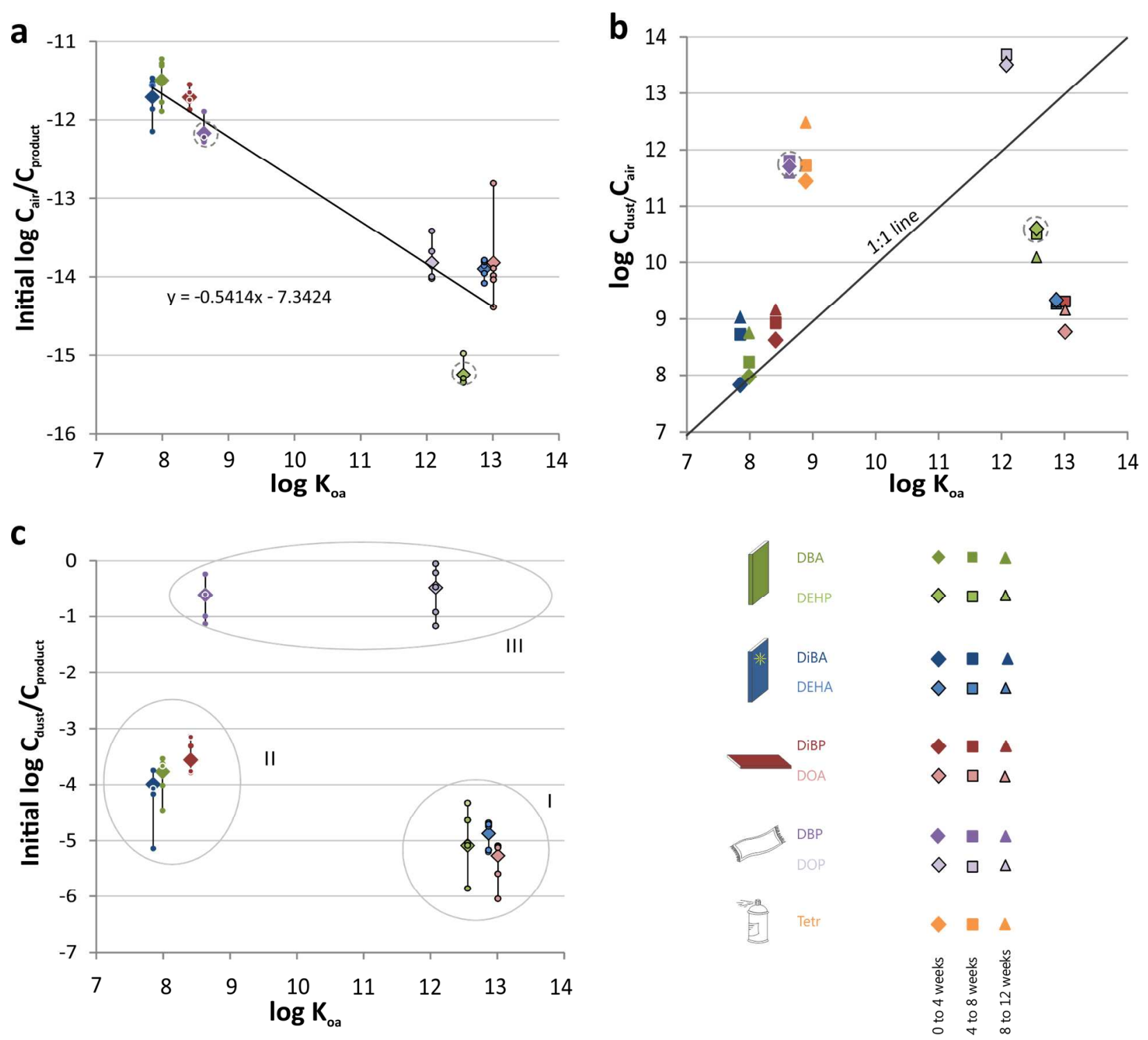

Figure S13. Correlation between $\mathrm{C}_{\text {air }} / \mathrm{C}_{\text {product }}$ and default $\log \mathrm{K}_{\text {oa }}$ for the initial phase (a), $\mathrm{C}_{\text {dust }} / \mathrm{C}_{\text {air }}$ over time compared to $\log \mathrm{K}_{\text {oa }}(\mathrm{b}), \mathrm{C}_{\text {dust }} / \mathrm{C}_{\text {product }}$ for the initial phase compared to log $\mathrm{K}_{\text {oa }}$ (c). The error bars represent the variability of concentration ratios in single apartments. 


\section{References}

(1) Piringer, O. G.; Baner, J. Plastic Packaging: Interactions with Food and Pharmaceuticals, 2nd ed.; WILEY-VCH Verlag GmbH \& Co. KGaA: Weinheim, 2008.

(2) Bohlin, P.; Audy, O.; Škrdlíková, L.; Kukučka, P.; Přibylová, P.; Prokeš, R.; Vojta, š.; Klánová, J. Outdoor passive air monitoring of semi volatile organic compounds (SVOCs): a critical evaluation of performance and limitations of polyurethane foam (PUF) disks. Environ. Sci. Process. Impacts 2014, 16 (3), 433.

(3) Zhang, G.; Chakraborty, P.; Li, J.; Sampathkumar, P.; Balasubramanian, T.; Kathiresan, K.; Takahashi, S.; Subramanian, A.; Tanabe, S.; Jones, K. C. Passive Atmospheric Sampling of Organochlorine Pesticides, Polychlorinated Biphenyls, and Polybrominated Diphenyl Ethers in Urban, Rural, and Wetland Sites along the Coastal Length of India. Environ. Sci. Technol. 2008, 42 (22), 8218-8223.

(4) Weschler, C. J.; Nazaroff, W. W. SVOC partitioning between the gas phase and settled dust indoors. Atmos. Environ. 2010, 44 (30), 3609-3620.

(5) Fergusson, J. E.; Forbes, E. A.; Schroeder, R. J.; Ryan, D. E. The elemental composition and sources of house dust and street dust. Sci. Total Environ. 1986, 50, 217-221.

(6) Mølhave, L.; Schneider, T.; Kjærgaard, S. K.; Larsen, L.; Norn, S.; Jørgensen, O. House dust in seven Danish offices. Atmos. Environ. 2000, 34 (28), 4767-4779.

(7) Standard Guide for Using Indoor Carbon Dioxide Concentrations to Evaluate Indoor Air Quality and Ventilation; Standard D6245-12; American Society for Testing and Materials (ASTM): West Conshohocken, PA, 2012.

(8) Standard Test Method for Determining Air Exchange in a Singe Zone my Means of a Tracer Gas Dilution; Standard E741-00; American Society for Testing and Materials (ASTM): West Conshohocken, PA, 2006.

(9) Weschler, C. J.; Nazaroff, W. W. Semivolatile organic compounds in indoor environments. Atmos. Environ. 2008, 42 (40), 9018-9040.

(10) Schripp, T.; Salthammer, T.; Fauck, C.; Bekö, G.; Weschler, C. J. Latex paint as a delivery vehicle for diethylphthalate and di-n-butylphthalate: Predictable boundary layer concentrations and emission rates. Sci. Total Environ. 2014, 494-495, 299-305. 
(11) Dodson, R. E.; Camann, D. E.; Morello-Frosch, R.; Brody, J. G.; Rudel, R. A. Semivolatile Organic Compounds in Homes: Strategies for Efficient and Systematic Exposure Measurement Based on Empirical and Theoretical Factors. Environ. Sci. Technol. 2015, 49 (1), 113-122.

(12) Turpin, B. J.; Lim, H.-J. Species Contributions to PM2.5 Mass Concentrations: Revisiting Common Assumptions for Estimating Organic Mass. Aerosol Sci. Technol. 2001, 35 (1), 602-610.

(13) Fromme, H.; Lahrz, T.; Hainsch, A.; Oddoy, A.; Piloty, M.; Rüden, H. Elemental carbon and respirable particulate matter in the indoor air of apartments and nursery schools and ambient air in Berlin (Germany). Indoor Air 2005, 15 (5), 335-341. 